\title{
An assessment of the antibacterial activity in larval excretion/secretion of four species of insects recorded in association with corpses, using Lucilia sericata Meigen as the marker species
}

\author{
K.M. Barnes ${ }^{*} \dagger$, D.E. Gennard and R.A. Dixon \\ Department of Forensic and Biomedical Sciences, University of Lincoln, \\ Brayford Pool, Lincoln, UK LN6 7TS
}

\begin{abstract}
The relative antibacterial activities of excretion/secretion (ES) from two carrionfeeding insects, Calliphora vicina Robineau-Desvoidy and Dermestes maculatus DeGeer, and a detritivore, Tenebrio molitor Linnaeus, were compared to that of Lucilia sericata Meigen, a species with ES of known antibacterial capacity, in order to explore the antimicrobial potential of other carrion and detritivore species. Viable counts were used to assess time-kill of ES against five bacterial species, Staphylococcus aureus, Escherichia coli, Bacillus cereus, Pseudomonas aeruginosa and Proteus mirabilis. Antibacterial activity was recorded in all four insect species although T. molitor and D. maculatus were the most effective in controlling growth of $P$. mirabilis. The blowflies were more effective in controlling a wider range of both Gram-positive and Gram-negative bacteria. The larval ES from all species was shown to reduce bacterial growth rate although differences in antibacterial spectrum were noted and the degree of potency varied between the four species. These differences may be explained ecologically by the different colonisation times of each insect species on the corpse. Overall, this study demonstrates that research into other carrion-feeding insect species has potential to provide an increased source of antimicrobial chemicals to broaden the range of bacterial species beyond that currently controlled using L. sericata.
\end{abstract}

Keywords: Lucilia sericata, Calliphora vicina, Tenebrio molitor, Dermestes maculatus, antibacterial, secretions

(Accepted 5 November 2009)

\section{Introduction}

Dead bodies and detritus provide nutrient sources and an oviposition site for some insect species. In such environments, the newly hatched larvae are exposed to

*Author for correspondence

Fax: +44 (0) 1142254449

E-mail: K.Barnes@shu.ac.uk

${ }^{\dagger}$ Current address: Department of Biosciences, Sheffield Hallam University, City Campus, Sheffield, S1 1WB, UK microorganisms, both immediately and as decomposition progresses. Such insects are under strong selective pressure to resist infection and maintain an effective immune response.

In addition to internal immune resources such as coagulation, phagocytosis, encapsulation and nodule formation (Sadd \& Siva-Jothy, 2006), some insects are equipped with external antimicrobial defences. An example is provided by Hoback et al. (2004), who showed oral secretions from several Nicrophorus beetle species and anal secretions from one species of Silphinae were active against Vibrio fischerii bacteria. Early twentieth century studies 
demonstrated antibacterial activity in external excretions/ secretions (ES) from diptera such as Lucilia sericata (Meigen), Calliphora species and Phormia terraenovae (RobineauDesvoidy) (Simmons, 1935; Gwatkin \& Fallis, 1938; Pavillard \& Wright, 1957), species which are carrion feeders. Recent work has extended this knowledge in the context of L. sericata and shown that ES from sterile larvae is antibacterial against organisms such as MRSA (Thomas et al., 1999; Bexfield et al., 2004; Kerridge et al., 2005; Huberman et al., 2007a). The antimicrobial activity has been identified from two fractions of the ES, one between 0.5 and $10 \mathrm{KDa}$ and a second at less than $500 \mathrm{Da}$. The antimicrobial constituent from the latter fraction has been patented under the name 'Seraticin $\mathbb{R}$ ' (Bexfield et al., 2008).

The success of this recent work signals the need to review the antimicrobial capabilities of other insects inhabiting carrion and detritus in order to determine their potential for controlling a wider range of microorganisms. The present study investigated the antibacterial activities of un-induced ES from larvae of a comparable initial coloniser, Calliphora vicina (Robineau-Desvoidy) and two beetle species modelling colonisers of later stages of decomposition, Dermestes maculatus (DeGeer) and Tenebrio molitor (Linnaeus). The antibacterial activities of their un-induced ES are compared to that of ES from L. sericata larvae.

\section{Materials and methods}

Bacterial viable counts were used to assess the antibacterial potency of ES from each of the four larval species against five bacterial reference species: Staphylococcus aureus (ATCC 25923), Escherichia coli (ATCC 25922), Pseudomonas aeruginosa (ATCC 27853), Proteus mirabilis (ATCC 43071) and Bacillus cereus (NCIMB 3329). On at least two separate occasions, each experiment was replicated three times.

\section{Marker insect species}

Lucilia sericata, a member of the Calliphoridae, was used as the marker species as it has been studied intensively for decades as a result of its use in maggot debridement therapy (Simmons, 1935; Thomas et al., 1999; Mumcuoglu et al., 2001; Lerch et al., 2003; Bexfield et al., 2004, 2008; Kerridge et al., 2005; Reinecke et al., 2005; Daeschlein et al., 2007; Huberman et al., 2007b; Jaklic et al., 2008; van der Plas et al., 2008). Calliphora vicina, also an initial coloniser, was used as a comparison to $L$. sericata since less is known about this species' antimicrobial excretion/secretion (Gwatkin \& Fallis, 1938). Dermestes maculatus colonises a corpse during the decay stages of decomposition (Kulshrestha \& Satpathy, 2001; Oliva, 2001; Grassberger \& Frank, 2004), and Tenebrionidae, such as T. molitor, have been associated with a corpse during the dry stages of decay (Mégnin, 1894; Arnaldos et al., 2005; Gennard, 2007).

\section{Larval ES preparation}

Colonies of the Calliphoridae and $T$. molitor were maintained under a lighting regime of $16: 8 \mathrm{~h}(\mathrm{~L}: \mathrm{D})$, whilst cultures of $D$. maculatus were maintained in complete darkness. Lucilia sericata and C. vicina larvae were reared on a diet of ad libitum porcine liver and D. maculatus and T. molitor on dried porcine cubes supplemented with working dog biscuits. All colonies were maintained at a temperature of $25^{\circ} \mathrm{C} \pm 3^{\circ} \mathrm{C}$.

The excretion/secretion (ES) was collected from each species by adding a standardised amount of sterile, deionised water to a sample of larvae which were weighed and the numbers adjusted to give a fixed ratio of maggots to water $\left(1 \mathrm{~g} \mathrm{ml}^{-1}\right)$. (Blowfly larvae were collected whilst in the third instar and beetle larvae from actively feeding stages with a standard length of $12 \pm 1 \mathrm{~mm}$ for D. maculatus and $26 \pm 2 \mathrm{~mm}$ for T. molitor). Larvae were incubated at $30^{\circ} \mathrm{C}$ for $60 \mathrm{~min}$ (a method adapted from Bexfield et al., 2004), after which ES was collected and micro-centrifuged at $7826 \times g$ for five minutes and filtered $(0.20 \mu \mathrm{m})$ to remove large particles and bacteria. The ES from each insect species was then stored frozen at $-20^{\circ} \mathrm{C}$ until required.

\section{Representative bacterial species}

The bacterial species were chosen on the basis that they were representative of the changing micro-organism populations on a body during decomposition. There has been very limited research on the succession of microbial species on a corpse during decomposition, and information about species, location and growth requirements on live bodies and habitats were the criteria used to determine which bacteria were to be chosen: Staphylococci as common skin bacteria; E. coli and P. mirabilis from the gut; and B. cereus, $P$. mirabilis and $P$. aeruginosa associated with the environment, being present in soil and decomposing materials.

\section{Preparation of bacteria}

One colony was removed from a stock plate of nutrient agar (Oxoid Ltd, Basingstoke, Hampshire, England) and was inoculated into $20 \mathrm{ml}$ sterile tryptone soya broth (TSB) (Oxoid Ltd, Basingstoke, Hampshire, England). The broth was incubated at $37^{\circ} \mathrm{C}$ with shaking for $17 \mathrm{~h}$. A sample of $0.1 \mathrm{ml}$ of the overnight bacterial culture was transferred to $10 \mathrm{ml}$ TSB broth and incubated at $37^{\circ} \mathrm{C}$ with shaking until the optical density reading at $600 \mathrm{~nm}$ was in the range of $0.24-0.25$.

\section{Confirmation of antibacterial activity in ES from the marker species, Lucilia sericata}

The antibacterial activity of L. sericata ES was quantified using liquid culture assays employing $10 \%$ TSB and $\mathrm{dH}_{2} \mathrm{O}$ or ES to confirm its antibacterial activity before being used as the marker species in the experiments reported in this paper. Results demonstrated that L. sericata ES had a significant inhibitory action and that there was $>99 \%$ less bacterial growth in ES than controls throughout a 24-h period (data not shown).

\section{Sample preparation}

To investigate the antibacterial activity of ES from C. vicina, D. maculatus and T. molitor against the known activity of $L$. sericata, defrosted insect excretion/secretion (ES) from each species was separated into $4 \mathrm{ml}$ aliquots. The purpose of this study was to model the antibacterial activity of ES in the insects' natural environment. Therefore, additional media was not employed in this assay, particularly as its effect on antibacterial activity of ES was not 


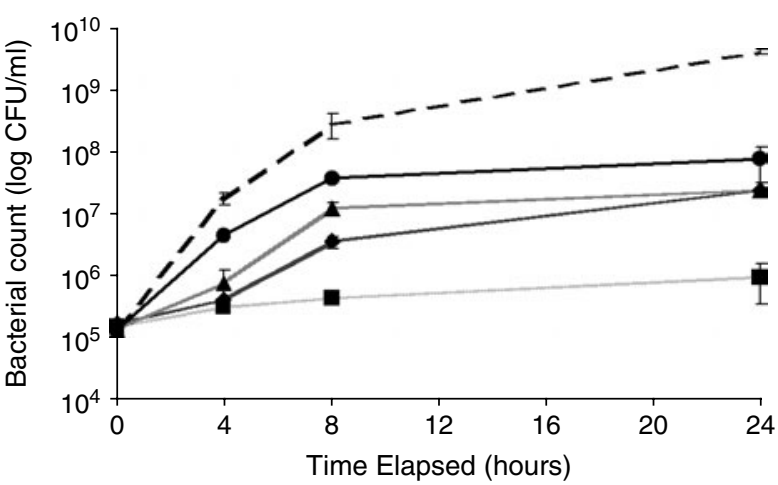

Fig. 1. A typical 24-h growth curve with aeration of Staphylococcus aureus in ES from Lucilia sericata, Calliphora vicina, Dermestes maculatus and Tenebrio molitor (error bars indicate 95\% confidence intervals). The control represents normal bacterial growth $(-\ldots \ldots$, L. sericata $E S$; $\longrightarrow$, C. vicina $E S$; --, D. maculates ES; - _-, T. molitor ES;--, control).

known. In order to demonstrate the pattern of normal bacterial growth, $4 \mathrm{ml}$ aliquots of TSB $/ \mathrm{dH}_{2} \mathrm{O}$ were utilised as controls to replace the ES. Twenty $\mu \mathrm{l}$ of bacteria in TSB was added to all aliquots and the universals incubated at $37^{\circ} \mathrm{C}$, with aeration, for a $24-\mathrm{h}$ period.

\section{Effectiveness of bacterial control}

Viable counts were prepared on nutrient agar at zero, four, eight and $24 \mathrm{~h}$ after inoculation for each of the four insect species and the controls. The agar plates were incubated at $37^{\circ} \mathrm{C}$ for $20-24 \mathrm{~h}$ and viable counts (CFU ml ${ }^{-1}$ ) were used to provide a quantitative determination of bacterial growth.

\section{Confirmation of absence of contamination}

To confirm the sterility of samples of ES prior to bacterial inoculation, a loop $(10 \mu \mathrm{l})$ of ES from each insect, TSB, and sterile $\mathrm{dH}_{2} \mathrm{O}$ were spread separately onto nutrient agar and incubated at $37^{\circ} \mathrm{C}$ for $24 \mathrm{~h}$. This procedure was repeated at four, eight and $24 \mathrm{~h}$ to ensure the media used to prepare dilutions for viable counts was contamination-free.

\section{Statistical analyses}

Statistical analyses were performed using SPSS (version 14.0) on $\log _{10}$ transformed mean count data sets to compare bacterial growth in ES from the three insect species in relation to growth in ES from L. sericata. The Bonferroni test was used as a post hoc test on those significantly different data sets confirmed by ANOVA. The results are presented as the mean bacterial count over a 24 -h period.

\section{The $p H$ of insect ES}

The $\mathrm{pH}$ of each aliquot of ES was recorded prior to each experiment in order to observe possible effects on antibacterial activity. No attempt was made to alter the $\mathrm{pH}$ of the ES as the intention was to observe its antibacterial activity in its natural state.

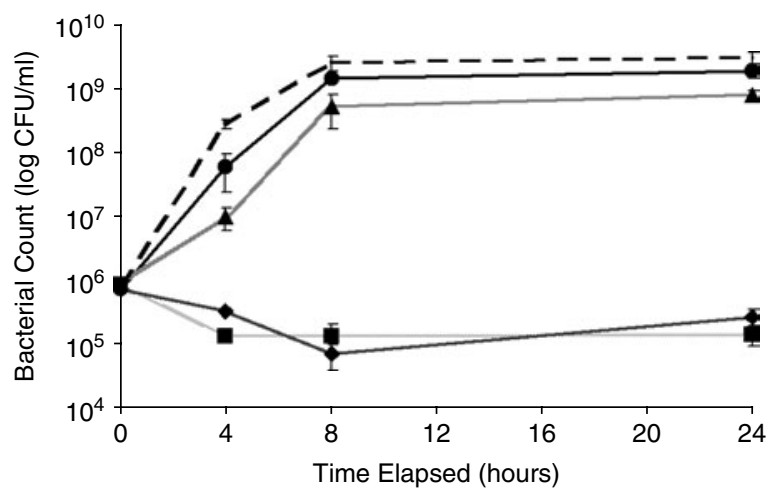

Fig. 2. A typical growth curve over a 24-h period with aeration of Escherichia coli in ES from Lucilia sericata, Calliphora vicina, Dermestes maculatus and Tenebrio molitor (error bars indicate 95\% confidence intervals). The control reflects normal bacterial growth (- - L sericata ES; $\longrightarrow, C$. vicina ES; - D. maculates ES; - $\longrightarrow$, T. molitor ES; --, control).

\section{Results}

A repeated measures ANOVA indicated that there was a significant difference between the mean bacterial counts in ES from each insect species $\left(F_{3,27}=5.43, P=0.005\right)$. A Bonferroni post hoc test revealed no significant difference between the antibacterial effectiveness of ES from $L$. sericata and $C$. vicina against the five bacterial species $(P=1.00)$. Nor was any significant difference noted between the antibacterial activity of $L$. sericata and T. molitor $(P=0.128)$. However, L. sericata was significantly more effective at inhibiting the growth of the five bacterial species than $D$. maculatus $(P=0.006)$.

\section{Staphylococcus aureus (ATCC 25923)}

All insect species allowed some growth of $S$. aureus (fig. 1). Of the species compared, L. sericata was shown to be the most effective source of antibacterial ES for controlling S. aureus.

\section{Escherichia coli (ATCC 25922)}

Both Calliphorids exhibited good bactericidal activity against E. coli. Lucilia sericata and C. vicina ES inhibited E. coli growth over the 24-h period (fig. 2), reducing the mean bacterial count by $84 \%$ and $63 \%$, respectively. Over the first four hours, C. vicina ES reduced the initial count of $E$. coli by $55 \%$; over an 8-h period, the bacterial count was $91 \%$ less than the original inoculum. In contrast, bacteria treated with ES from T. molitor and D. maculatus showed exponential growth so that over eight hours there was a $10^{2}$ increase in bacterial population, indicating that they were not an effective means of control of this species.

\section{Bacillus cereus (NCIMB 3329)}

There was also a significant difference in the antibacterial effectiveness of the four insects' ES in controlling bacterial growth over a $24-\mathrm{h}$ period. In the first four hours, both L. sericata and C. vicina ES (fig. 3) demonstrated a $100 \%$ bacterial count reduction of B. cereus. They were, therefore, 


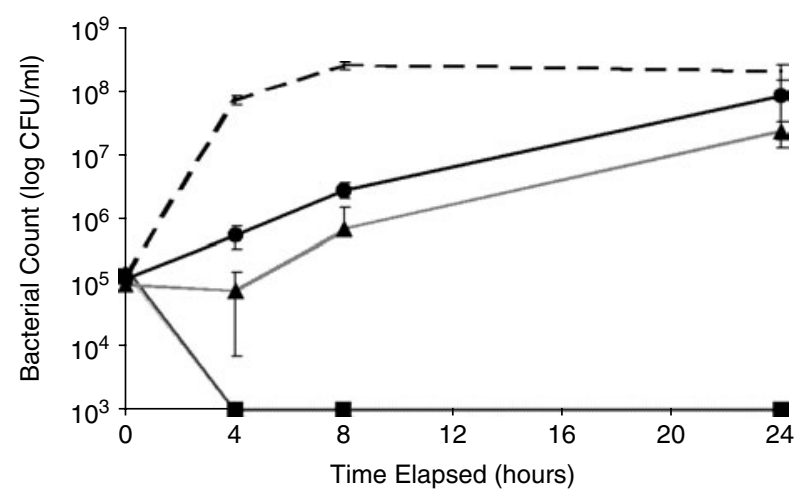

Fig. 3. A typical Bacillus cereus growth curve over a 24-h period with aeration in ES from Lucilia sericata, Calliphora vicina, Dermestes maculatus and Tenebrio molitor (error bars indicate 95\% confidence intervals). The control represents normal bacterial growth $(-\mathbf{-}-$, L. sericata $E S$; $\longrightarrow$, C. vicina $E S$; --, D. maculates ES; -__-, T. molitor ES; --, control).

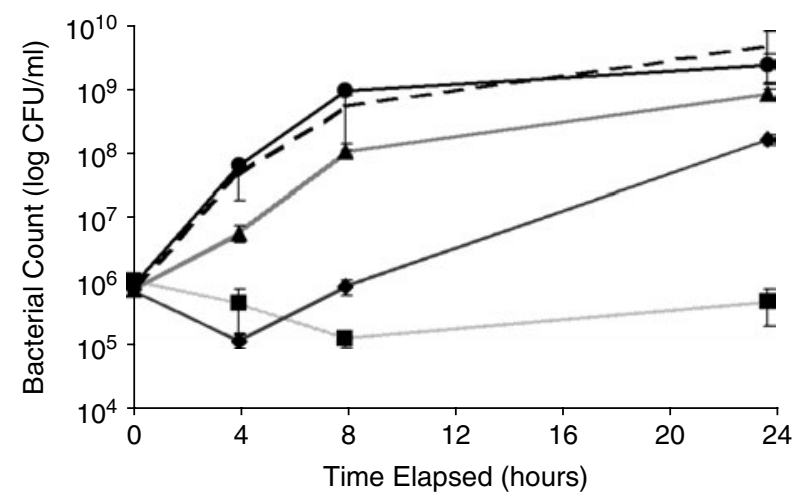

Fig. 4. A typical growth curve of Pseudomonas aeruginosa in ES from Lucilia sericata, Calliphora vicina, Dermestes maculatus and Tenebrio molitor over a 24-h period with aeration (error bars indicate $95 \%$ confidence intervals). The control reflects normal bacterial growth $(-\ldots-$, L. sericata ES; $\longrightarrow-$, C. vicina ES; --, D. maculates ES; -——, T. molitor ES; --, control).

much more efficient at inhibiting the growth of B. cereus than the ES of either D. maculatus or T. molitor, although the latter inhibited bacterial growth in the first four hours.

\section{Pseudomonas aeruginosa (ATCC 27853)}

$P$. aeruginosa was effectively inhibited over $24 \mathrm{~h}$ by L. sericata ES (fig. 4) and ES from both blowflies was bactericidal during the first four hours of growth. Over the first four hours, C. vicina ES was the more effective and reduced the mean bacterial count by $85 \%$, whilst $L$. sericata ES only reduced it by $58 \%$. However, over $24 \mathrm{~h}$, L. sericata ES maintained its bacteriostatic activity (55\% mean bacterial count reduction), whereas C. vicina $\mathrm{ES}$ allowed re-growth to occur in the period between eight and $24 \mathrm{~h}$. In contrast, ES from both $D$. maculatus and T. molitor were an ineffective means of controlling $P$. aeruginosa since both allowed growth throughout the 24-h period.

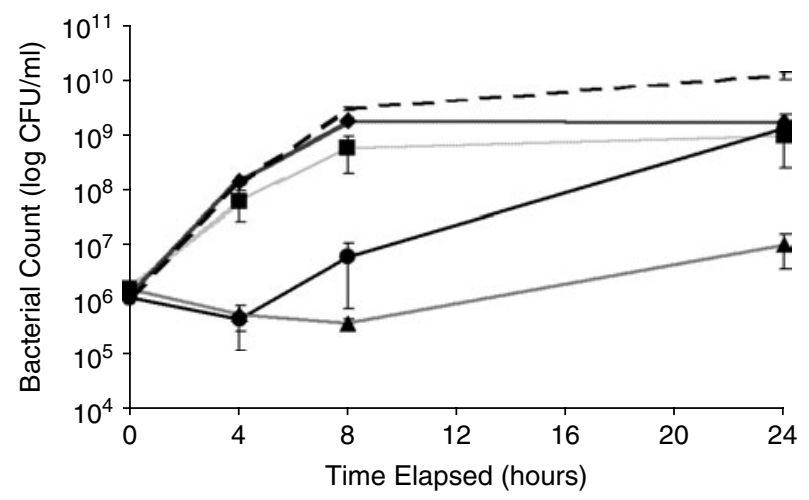

Fig. 5. Line graph showing a typical growth curve of Proteus mirabilis in ES from Lucilia sericata, Calliphora vicina, Dermestes maculatus and Tenebrio molitor over a 24-h period with aeration (error bars indicate 95\% confidence intervals). The control represents normal bacterial growth (- - - L. sericata ES; $\longrightarrow$, C. vicina ES; - $;-$, D. maculates ES; _- $\longrightarrow$ T. molitor ES; --, control).

\section{Proteus mirabilis (ATCC 43071)}

Interestingly, beetle ES was much more effective against P. mirabilis, whilst blowfly ES had no effect (fig. 5). By the end of a four-hour period, there was a $60 \%$ mean bacterial count reduction in D. maculatus ES and a $66 \%$ mean bacterial count reduction in T. molitor ES although, after this point, D. maculatus ES allowed bacterial re-growth. Tenebrio molitor ES continued to inhibit the growth of $P$. mirabilis for a further four hours (77\% mean bacterial count reduction). Therefore, T. molitor ES was more efficient at inhibiting the growth of P. mirabilis than ES from L. sericata, C. vicina or D. maculatus.

\section{The effect of $\mathrm{pH}$ on antibacterial activity of ES}

The $\mathrm{pH}$ of ES from each insect had different ranges: L. sericata (8.67-8.82); C. vicina (8.53-8.68); D. maculatus (6.00-6.14); and T. molitor (5.14-5.28). However, a two-tailed Pearson's test demonstrated that there was no significant linear correlation between the $\mathrm{pH}$ of insect ES and its antibacterial potency against the five bacterial species tested. This was true for $L$. sericata ES $(\mathrm{r}=-0.09, n=10, P=0.815)$, C. vicina ES $(\mathrm{r}=0.07, n=10, P=0.859)$, D. maculatus ES $(\mathrm{r}=0.109, n=10, P=0.776)$ and T. molitor ES $(\mathrm{r}=-0.448$, $n=10, P=0.194)$. Therefore, $\mathrm{pH}$ did not influence antibacterial activity of ES from these species.

\section{Discussion}

All four insect species demonstrated differences in their potency against each of the five species of bacteria. However, viable counts showed that, at the concentration tested, ES from all species was capable of reducing bacterial numbers for at least part of a $24-\mathrm{h}$ period (figs $1-5$ ); no lag phase was observed during this period.

The viable count results for $L$. sericata ES confirm those reported by Bexfield et al. (2008), who showed a $97.4 \%$ decrease in $E$. coli populations over a six-hour period. In contrast, research by Jaklic et al. (2008) established a prolonged lag phase of 5-6h for E. coli, after which exponential growth occurred. He demonstrated this same lag 
phase for P. aeruginosa, which is also in contrast to the results reported here.

However, an equivalent level of antibacterial potency against S. aureus reported by both Bexfield et al. (2008) and Jaklic et al. (2008) was not demonstrated in this study. Bexfield et al. (2008) showed that, after a six-hour period, L. sericata ES was able to reduce the population of $S$. aureus $\left(10^{6}\right)$ by $91.5 \%$, and Jaklic et al. (2008) demonstrated a $100 \%$ reduction of $S$. aureus after eight hours. These differences may be due to variation in concentration of ES, the types of media used for the liquid culture assay or the duration of the experimental period between these three studies.

Previous researchers have suggested that the $\mathrm{pH}$ of insect ES influenced its antibacterial activity (Gwatkin \& Fallis, 1938; Thomas et al., 1999; Bexfield et al., 2004). Therefore, the origin of the antibacterial activity demonstrated in the insect ES was explored by investigating the $\mathrm{pH}$ ranges of ES from each insect species. Typically, the ES from L. sericata and C. vicina was alkaline ( $\mathrm{pH} 8-9)$ compared to the ES from D. maculatus and T. molitor, which was found to be acidic (pH5-6). However, there was no significant correlation between the $\mathrm{pH}$ of insect ES and bacterial growth, indicating $\mathrm{pH}$ had no effect on antibacterial potency. These results support work conducted by Bexfield et al. (2004), who showed that antibacterial activity in L. sericata ES was not dependant on the alkaline condition, by changing the $\mathrm{pH}$ of L. sericata ES and demonstrating the same antibacterial activity existed in aliquots that were altered to $\mathrm{pH} 6$ and 7 as was in native ES ( $\mathrm{pH} 8-9)$. Therefore, it appears that the effectiveness of insect ES relates to agents other than $\mathrm{pH}$.

The fact that larval ES did not always maintain an antibacterial effect over the 24-h experimental period does not minimise its potential as an antibacterial agent. Data from several experiments demonstrated that larval ES is produced continuously (unpublished data); therefore, even short-lived antibacterial activity would still be an effective defence against microbes on a corpse.

The difference in antibacterial potency and spectrum between the blowflies and the beetles is not altogether surprising and may be explained ecologically by the fact that blowflies tend to frequent habitats with potentially more diverse species of bacteria present. As the initial colonisers of a corpse, blowflies encounter bacteria originating from the human body. As a corpse decomposes, production of waste gases extends the body until, eventually, the skin is broken, allowing the gut bacteria (and gases) to escape. It is assumed that most obligate anaerobes will die off at this stage; but facultative anaerobes, such as Proteus and E. coli, will survive and be in direct competition with the insects now feeding on the corpse.

Beetle larvae are generally present on a corpse in the later stages of decomposition (advanced and post decay), when much of the soft tissue has been removed. It is assumed that most human-derived bacteria have been reduced in number by earlier insect colonisers and that bacteria from the environment probably dominate. Bacterial species, such as $P$. mirabilis, against which the beetle but not blowfly larvae ES in this study were active, may potentially be present at the time of coleopteran colonisation.

The blowflies, L. sericata and C. vicina, produced excretion/secretion (ES), which was active against both the Gram-positive and Gram-negative bacteria tested in this study. This secretion/excretion had a broader spectrum and a more potent antibacterial activity than the ES of either of the beetles, D. maculatus and T. molitor. The blowflies were able to inhibit or reduce growth of four out of the five bacterial species used, whereas the beetles were only effective against one, $P$. mirabilis. These results indicate the potential of using ES from carrion-feeding coleoptera as antibacterial agents, as well as those of Calliphoridae, and that the poorer antibacterial capacity may reflect the bacterial contact in the habitat to which the beetles, in contrast to the Calliphorids, are exposed.

\section{Acknowledgements}

We would like to thank John Flynn for statistical advice and support.

\section{References}

Arnaldos, M.I., Garcia, M.D., Romera, E., Presa, J.J. \& Luna, A. (2005) Estimation of post-mortem interval in real cases based on experimentally obtained entomological evidence. Forensic Science International 149, 57-65.

Bexfield, A., Nigam, Y., Thomas, S. \& Ratcliffe, N.A. (2004) Detection and partial characterisation of two antibacterial factors from the excretions/secretions of the medicinal maggot Lucilia sericata and their activity against methicillinresistant Staphylococcus aureus (MRSA). Microbes and Infection 6(14), 1297-1304.

Bexfield, A., Bond, A.E., Roberts, E.C., Dudley, E., Nigam, Y., Thomas, S., Newton, R.P. \& Ratcliffe, N.A. (2008) The antibacterial activity against MRSA strains and other bacteria of a $<500 \mathrm{Da}$ fraction from maggot excretions/ secretions of Lucilia sericata (Diptera: Calliphoridae). Microbes and Infection 10, 325-333.

Daeschlein, G., Mumcuoglu, K.Y., Assadian, O., Hoffmeister, B. \& Kramer, A. (2007) In Vitro Antibacteral Activity of Lucilia sericata Maggot Secretions. Skin Pharmacology and Physiology 20, 112-115.

Gennard, D.E. (2007) Forensic Entomology: An Introduction. Chichester, UK, John Wiley and Sons Ltd.

Grassberger, M. \& Frank, C. (2004) Initial study of arthropod succession on pig carrion in a central European urban habitat. Journal of Medical Entomology 41(3), 511-523.

Gwatkin, R. \& Fallis, A.M. (1938) Bactericidal and antigenic qualities of the washings of blowfly maggots. Canadian Journal of Research 16(12), 343-352.

Hoback, W.W., Bishop, A.A., Kroemer, J., Scalzitti, J. \& Shaffer, J.J. (2004) Differences among antimicrobial properties of carrion beetle secretions reflect phylogeny and ecology. Journal of Chemical Ecology 30(4), 719-729.

Huberman, L., Gollop, N., Mumcuoglu, K.Y., Block, C. \& Galun, R. (2007a) Antibacterial properties of whole body extracts and haemoloymph of Lucilia sericata maggots. Journal of Wound Care 16(3), 123-127.

Huberman, L., Gollop, N., Mumcuoglu, K.Y., Breuer, E., Bhusare, S.R., Shai, Y. \& Galun, R. (2007b) Antibacterial substances of low molecular weight isolated from the blowfly, Lucilia sericata. Medical and Veterinary Entomology 21(2), 127-131.

Jaklic, D., Lapanje, A., Zupancic, K., Smrke, D. \& GundeCimerman, N. (2008) Selective antimicrobial activity of maggots against pathogenic bacteria. Journal of Medical Microbiology 57, 617-625. 
Kerridge, A., Lappin-Scott, H. \& Stevens, J.R. (2005) Antibacterial properties of larval secretions of the blowfly, Lucilia sericata. Medical and Veterinary Entomology 19, 333337.

Kulshrestha, P. \& Satpathy, D.K. (2001) Use of beetles in forensic entomology. Forensic Science International 120, 15-17.

Lerch, K., Linde, H.-J., Lehn, N. \& Grifka., J. (2003) Bacteria ingestion by blowfly larvae: an in vitro study. Dermatology 207, 306-366.

Mégnin, P. (1894) La Faune des Cadavres: Application de l'Entomologie a la Médicine Légale. Paris, France, G. Masson.

Mumcuoglu, K.Y., Miller, J., Mumcuoglu, M., Friger, M. \& Tarshis, M. (2001) Destruction of bacteria in the digestive tract of the maggot Lucilia sericata (Diptera: Calliphoridae). Journal of Medical Entomology 38(2), 161-166.

Oliva, A. (2001) Insects of forensic significance in Argentina. Forensic Science International 120, 145-154.

Pavillard, E.R. \& Wright, E.A. (1957) An antibiotic from maggots. Nature 180, 916-917.
Reinecke, M., Mayer, G. \& Heisig, P. (2005) Lucilia sericata: latest results of antibacterial activity (Abstract). 15th European Congress of Clinical Microbiology and Infectious Diseases. 2-5 April 2005, Copenhagen, Denmark.

Sadd, B.M. \& Siva-Jothy, M.T. (2006) Self-harm caused by an insect's innate immunity. Proceedings of the Royal Society: Part B, Biological Sciences 273(1600), 2571-2574.

Simmons, S.W. (1935) The bactericidal properties of excretions of the maggot Lucilia sericata. Bulletin of Entomological Research 26, 559-563.

Thomas, S., Andrews, A.M., Hay, N.P. \& Bourgoise, S. (1999) The anti-microbial activity of maggot secretions: results of a preliminary study. Journal of Tissue Viability 9(4), 127-132.

van der Plas, M.J.A., Jukema, G.N., Wai, S-W., DogteromBallering, H.C.M., Lagendijk, E.L., van Gulpen, C., van Dissel, J.T., Bloemberg, G.V. \& Nibbering, P.H. (2008) Maggot excretions/secretions are differentially effective against biofilms of Staphylococcus aureus and Pseudomonas aeruginosa. Journal of Antimicrobial Chemotherapy 61, 117-122. 